\title{
Effect of cotton dust on lung functions
}

\author{
Mohammed Kh. Ibrahim* Baybeen Kh. Alselevany** \\ *Ibin Sina Teaching Hospital, Mosul. **Department of Medical Physiology, Mosul, College of \\ Medicine, University of Mosul.
}

(Ann. Coll. Med. Mosul 2008; 34(2): 141-147).

Received: $9^{\text {th }}$ Sept 2007; Accepted: $11^{\text {th }}$ June 20008.

\begin{abstract}
Objectives: To assess the effect of cotton dust on pulmonary function tests of workers in a cotton textile factory.
\end{abstract}

Subjects and Methods: One hundred forty one male workers aged 21-60 years. Out of them 67 from Pepsi factory considered as controls, and 74 from cotton textile factory in Mosul , during the period from the $1^{\text {st }}$ of January 2007 to the $30^{\text {th }}$ of April 2007. The pulmonary function tests studied were :FVC ,FEVI , FEV\%.PEF and FEF25-75\%.

Results: Workers in cotton textile factory showed a significant reduction in the levels of FVC and of FEV1 at age of 40-60 years as compared to control workers.

Conclusions: The results showed that cotton dust causes a significant reduction in FVC and FEVI as age advances.



P ulmonary function testing is a valuable tool for the evaluation of the respiratory system. The pulmonary function tests (PET's) can diagnose lung diseases and measure the severity of lung problems ${ }^{(1)}$. The normal value ranges for PFT's will be adjusted for the subjects' age, height, sex and sometimes race ${ }^{(1)}$.

Pulmonary ventilation can be studied by many PFT's. Perhaps the following tests give enough information about the ventilatory function of the lungs ${ }^{(3-4)}$.

1. Forced Vital Capacity (FVC): The maximum volume of respiratory gas that can be forcefully expired following maximum inspiration. This is performed by having the subject to exhale forcibly, rapidly and completely following maximal inspiration. 
2. Forced Expiratory Volume in 1 second (FEV1): The maximum volume of gas that can be forcefully expired during the first second following maximal inspiration. It is relatively independent of effort. (FEV1) is the best single guide for assessment of ventilatory functional impairment, and if there is no restriction, this index reflects best the severity of airway obstruction ${ }^{(5)}$.

3. Forced Expiratory Ratio (FEV1\%):The percentage relationship between FEVI and FVC (FEV1 X 100IFVC). It can be regarded as a good test for early detection of obstructive pulmonary diseases $^{(6)}$.

4. Peak Expiratory Flow (PEF): The maximum forced expiratory flow rates achieved during single forced expiration. It may be expressed as liter per minute or liter per second and it is effort dependent and regarded as a complementary test and not a substitute for other tests ${ }^{(7)}$.

5. Forced Mid -Expiratory Flow (FEF25

(FMF):The mean forced expiratory flow rates achieved between $25 \%$ and $75 \%$ of the FVC during single forced expiration. It is relatively independent of effort and tends to reflect changes in small airways. It is very sensitive for indicating early airway obstruction or could be normal variant ${ }^{(8,9)}$.

A lot of work has been done during the past decades regarding the effect of age on various aspects of pulmonary function in many parts of the world. The lung function usually peaks in late teens and early twenties. After the early twenties, lung function declines about $1 \%$ a year over the rest of a person's life time. The values FEV1, FVC and MVV are significantly reduced with age of the subject ${ }^{(10-12)}$.

The word byssinosis is derived from Greek word "Breeo's" or Latin byssus. The word byssus meant fine soft, white fibers and probably originally referred to flax. The word bysssinosis became well known after its use by (Oliver $\mathrm{T}, 1909)^{(13)}$, in his books on occupational diseases.

Byssinosis has been defined as a respiratory disease associated with inhalation of cotton, flax, and hemp. The disease is found in many cotton processing countries. Some called it cotton dust asthma. It is more prevalent in the dusty stages of cotton processing such as carding, than in weaving. Chest tightness, cough, wheezing, dyspnoea in varying degrees are the initial symptoms. Similar symptoms have been also found in flax, hemp, jute and sisal workers The characteristic symptoms of byssinosis are shortness of breath and tightness of the chest on returning to the work after a period of absence. Byssinosis is characterized clinically as occasional (early) and then regular (late) chest tightness toward the end of the first day of work week (Monday chest tightness) $)^{(14)}$.

Eventually it is believed that irreversible obstructive airway diseases might occur.

The aim of the present study is to reevaluate the effect of dust in cotton textile factory on the respiratory system as judged by respiratory symptoms, clinical examination of the chest and lung function tests. If the case is so, some preventive measures may be suggested to the administrations of this factory in order to minimize the effect of dust on lung functions of the workers.

\section{Subjects and methods}

This study has been conducted during the period from the $1^{\text {st }}$ of January to the $30^{\text {th }}$ of April 2007. Lung function tests were carried out for 141 male workers aged 21- $60 \mathrm{yrs}$, from two factories in Mosul area. The subjects were then divided into two major groups according to place of work. Each was subgrouped according to age by 10 years (yrs) interval. Group 1 included 67 apparently healthy workers from Pepsi factory considered as controls. All control subjects were scrutinized for the absence of any cardio-pulmonary disease through history and physical examination. Group 2 consisted of 74 workers from cotton textile factory.

The plan of the study for each subject was as follows: case history, clinical examination of the chest, physical measurements, and pulmonary function tests as shown in figure 
I.A standardized questionnaire was patterned according to the American Thoracic Society questionnair\&15.This questionnaire is basically for respiratory system.

Pulmonary function tests were carried out by using Mijnhard Vicatest (VCT) Dry Type spirometer (Type VCT- 2) ${ }^{(16)}$.This instrument gives online calculation, digital display and recall of five essential parameters:

(FVC, FEVI, FEVI\%, PEF, and FEF) $(25.75 \%$ ). Tests were carried out during day time and in standing position, using a nose clip. The test subjects were always clearly and correctly instructed to inspire as deeply as possible, then to exhale as forcibly and as rapidly as possible into the mouth piece. They were asked to continue exhalation until they see the light switched on the spirometer indicating no more volume increase, thus getting consisted readings. All the gas volumes were measured at ambient temperature and pressure saturated with water vapor (ATPS), but are corrected to body temperature and pressure saturated with water vapor (BTPS) before comparison with normal or predicted values to ensure an accurate interpretation of the respiratory $\operatorname{data}^{(16)}$.

Statistical analysis was performed by analysis of variance (ANOVA) and

using unpaired student T-test, and "Duncan multiple rang test" ${ }^{\text {"17). }}$. All values were expressed as mean $\pm S D$. Results were considered significant at $\mathrm{P} \leq 0.05$.

\section{Results}

The effect age on the pulmonary function Tests

Figure (2) shows that there was an increment in the percentage (\%) of workers with abnormal lung function tests in cotton textile factory, accompanied with advancing age. The lowest percentage was $(19 \%)$ at age 21 -3oyrs, increased to $(28 \%)$ at age 41 50 yrs and 51-6oyrs. In contrast to controls as the age increases, the percentages of workers with normal pulmonary functions were reduced. The highest value was $(43.4 \%)$ at age $21-30$ yrs diminished $(7.5 \%)$ at age 51-60yrs.

\section{The effect of cotton dust on pulmonary function tests}

The textile workers at the age of 41-50 yrs showed a significant reduction in FVC, and FEVI $(P<0.01)$ from that of control workers. Also at age of 51-60 years the value of FEVI was statistically lower in cotton textile workers as compared to controls, while no significant difference at all age groups in the levels of FEVI\%, PEF, and FEF25-75\% compared with controls as shown in(Table1).

Date of Examination: Address: Occupation: Duration:

Symptoms Asked According to ATS Questionnaire ${ }^{(17)}$

1. Cough: 2.phlegm(Sputum): Grade of Breathlessness:

4. Wheezing: 5 .Chest illness during the past 3 years:

6. Smokina habit: No. of ciaarette! dav: Duration:

Clinical Examination of the chest:

Previous History:

Family History:

Others:

Height: $\mathrm{Cm}$ Weight: $\mathrm{Kg}$ Room Temp.: 'C Correction Factor:

Parameters: Measured Values Corrected 123

1. FVC (L): 2. FEVI (L): 3.FEV\%: 4. MW (L 1mm): 5. PEF (L !Sec.):

6. FEF200.1205 (LISec): 7.FEF25.75\% (LIsec):

Figure1: A form used to record history, clinical examination of the chest and 




Figure(2): age distribution of controls and cotton textile group

Table (1): FVC, FEV1, FEV1 (\%), PEF and FEF2575\% .Mean \pm S.D of the cotton textile factory compared to control group according to age in decades.

\begin{tabular}{|c|c|c|c|c|c|}
\hline \multirow{2}{*}{ Parameters } & \multirow{2}{*}{$\begin{array}{c}\text { Groups } \\
\text { Age(yrs) }\end{array}$} & \multicolumn{2}{|c|}{ Controls } & \multicolumn{2}{|r|}{ Cotton Textile } \\
\hline & & 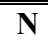 & Mean \pm S.D &  & "Mean \pm S.D. \\
\hline \multirow{4}{*}{ FVC (L) } & $21-30$ & 29 & $4.647 \pm 0.5$ & 13 & $4.582 \pm 0.3$ \\
\hline & $31-40$ & 23 & $4.448 \pm 0.4$ & 19 & $4.383 \pm 0.4$ \\
\hline & $41-50$ & 10 & $4.523 \pm 0.5$ & 21 & $3.684 \pm 0.4 * *$ \\
\hline & $51-60$ & 5 & $4.007 \pm 0.5$ & 21 & $3.387 \pm 0.7$ \\
\hline \multirow{4}{*}{ FEVI (L) } & $21-30$ & 29 & $4.183 \pm 0.4$ & 13 & $4.090 \pm 0.6$ \\
\hline & $31-40$ & 23 & $3.902 \pm 0.4$ & 19 & $4.052 \pm 0.4$ \\
\hline & 41-50 & 10 & $3.962 \pm 0.3$ & 21 & $3.353 \pm 0.4^{* * *}$ \\
\hline & $51-60$ & 5 & $3.785 \pm 0.3$ & 21 & $3.034 \pm 0.6^{*}$ \\
\hline \multirow{4}{*}{ FEVI (\%) } & $21-30$ & 29 & $88.6 \pm 7.0$ & 13 & $91.7 \pm 8.2$ \\
\hline & $31-40$ & 23 & $88.6 \pm 6.2$ & 19 & $92.3 \pm 6.1$ \\
\hline & $41-50$ & 10 & $88 \pm 11.3$ & 21 & $86.7 \pm 8.2$ \\
\hline & $51-60$ & 5 & $91.0 \pm 8$ & 21 & $86.04 \pm 10.5$ \\
\hline \multirow{4}{*}{ PEF (L/sec) } & 21-30 & 29 & $7.8 \pm 1.6$ & 13 & $8.8 \pm 2.8$ \\
\hline & $31-40$ & 23 & $9 \pm 3.8$ & 19 & $\mathbf{9} \pm \mathbf{3}$ \\
\hline & $41-50$ & 10 & $7.8 \pm 1.5$ & 21 & $8.8 \pm 3.2$ \\
\hline & $51-60$ & 5 & $8.7 \pm 2.9$ & 21 & $7.6 \pm 4.5$ \\
\hline \multirow{4}{*}{ FEF2 .\% (LI Sec) } & $21-30$ & 29 & $5.4 \pm 1$ & 13 & $5.5 \pm 1$ \\
\hline & $31-40$ & 23 & $5.1 \pm 0.9$ & 19 & $5.6 \pm 1.3$ \\
\hline & $41-50$ & 10 & $5.1 \pm 0.9$ & 21 & $4.6 \pm 0.9$ \\
\hline & 51-60 & 5 & $5.6 \pm 0.4$ & 21 & $4.3 \div 1.3$ \\
\hline
\end{tabular}

*= P<0.05; $\quad * *=P<0.01 ;$ L: litre.

\section{Discussion}

\section{Effect of age on pulmonary function tests}

the functional efficiency of the lung deteriorates with age ${ }^{(12)}$. A lot of crosssectional as well as longitudinal studies have been carried out to study the effect of age the lung function ${ }^{(11,12)}$. Aging is known to produce changes in many pulmonary functions ${ }^{(18)}$. The ideal approach to study the effect of age is repeatedly to determine the lung function in the same group of normal individuals over a number of years. In practice however, the evidence for the effect of aging can be obtained by comparing lung functions in normal people in different age groups ${ }^{(19)}$. 
In the present study, there was a decline in FVC with advancing age ${ }^{(20)}$. This is because the advancing age produces degenerative changes in musculoskeletal system of thoracoabdominal compartment. This imposes a limitation of maximal efforts for inspiration as well as expiration ${ }^{(21)}$. Loss of elasticity of lung tissue on accounts of aging produces relaxation of lung. The combined effect of loss of elastic properties of lung thorax system and reduced force of muscles of respiration leads to impairment of dynamic functions of ventilations as diminution of FEV1 and MW as age advances as was shown in this study ${ }^{(11,12)}$.

The decrease in FVC and FEV1 with advancing age was slow in the cross sectional study particularly between 35 and 45 years, while it was more pronounced and fairly linear in the longitudinal study ${ }^{(22)}$.

The FEV1 decline with age is more than the decline of FVC with age. This means that less volume of air during the first second of forced expiration could be expelled by older people. The explanation for this may be due to the fact that the ventilatory capacity is a function of respiratory muscle strength which declines with age. Also the resistance to movements of the lung and chest wall increases with age ${ }^{(23)}$ These findings are in agreement with results observed by Densen et al. (1969) ${ }^{(24)}$, who found a constant decrease in FEV1 value for all men between ages of 30 to 60 years. Poor muscular effort and loss of elasticity of lung tissues associated with aging process cause a decrease in PEF.

The reduction in FVC, and FEV1, with advancing age is in consistence with the findings of previous studies in this field ${ }^{(7-21)}$.

Effect of cotton dust on pulmonary function tests

Exposure to cotton dust occurs throughout the manufacturing process but is more pronounced in those portions of the factory involved with the treatment of cotton prior to spinning i.e. blowing, mixing, and carding (straightening of fibers).

In the present study FVC, and FEV1 generally showed lower values in cotton textile workers in all age groups aftter $40 \mathrm{yrs}$, there was a statistically significant reduction of these values when compared with the control workers, this reduction in FEVI indicate obstruction of the large airways and this goes with the diagnosis of byssinosis while there was no significant change in $\mathrm{FEVI} \%$ in cotton textile workers when compared to control workers.

In Greece, Kondakis and Fournares $(1965)^{(25)}$, found no clinical byssinosis among cotton workers. This is inconsistent with the findings of the present study. They also found a statistically significant reduction of FVC , FEVI and MVV in ginnery workers and a significant relationship between years of exposure to cotton and reduction of these values.

There is a significant correlation between chronic loss of pulmonary function and duration of exposure and level of the dust (years work in cotton mills). Long- term exposure to cotton dust, in which air-borne endotoxin appears to play an important role results in substantial adverse chronic respiratory effect ${ }^{(26)}$. The workers with a higher level of cumulative endotoxin exposure had significantly greater losses of FEV1 and FVC than those with a low level.

Endotoxin exposure was associated with faster lung function decline. Endotoxin is the principal component of cotton responsible for the development of inflammation of airway. Chronic occupational endotoxin exposure is associated with faster decline in lung function $^{(10)}$.

A survey by Cinkotai et al. in $1988^{(27)}$ of workers in 31 textile factories in Lancashire, United Kingdom, showed that byssinotic symptoms were related to years in the industry, degree of dust exposure, quality of cotton in use, ethnic origin of workers and smoking habit.

The conclusion from the above findings is that the workers in cotton factories will suffer from obstructive ventilatory defect. The findings of this study are consistent with the results of El-Sadik et al. (1982) ${ }^{(28)}$ who found that the nature of the disease caused by cotton dust was obstructive in type as judged by a reduction in FEV1 and improvement of 
obstructive features when the workers left the factory.

Because bacteria and fungi are present in large numbers in cotton dust several investigators have attempted to show a significant relationship between viable agents and byssinosis ${ }^{(29)}$. The lack of appropriate incubation period and the absence of. febrile illness along with daily recurrence of the chest tightness and rapid remission after leaving the mill were against this possibility ${ }^{(29,30)}$.

Cotton dust removal before it enters the mill may be the most important method to reduce dust related disease ${ }^{(31,32)}$.

\section{References}

1. Ruppel GL Manual of Pulmonary Function Testing. $7^{\text {th }}$ Ed St. Louis. Mosby. (1997).

2. Wagner $\mathrm{J}$ Pulmonary Function Testing: $A$ practical approach. Williams and Wilkins.(1996).

3. Borelli (1679). Cited by Fenn, W.O, and Rhan H., (1964). Hand Book of Physiology, section 3 , volume 1,1-62. American physiological society, Washington DC.

4. Pappenheimer JR Standardization of definitions and symbols in respiratory physiology. Fed. Proc (1950).9: 602.

5. Colp CR Interpretation of Pulmonary Function Testing. Chest 76: 377-378. (1997).

6. Sobol BJ. Park SS, Emigril R Relative value of various spirometric tests in the early detection of disease. Am Rev Resp Dis (1973).107: 753

7. Ritchie B A comparison of forced expiratory and peak flow in clinical practice, Lancet (1962).2: 271-273.

8. McFadden ER Jr, Liden DA A reduction in maximum mid- expiratory flow rate; $A$ spirographic manifestation of small air-way disease. Am J Med (1972).52: 725-737.

9. Lung Function Testing: Selection of reference values and interpretative strategies. American Thoracic Society Am Rev Respir Dis (1991).144: 1202-1224.

10. Hang $\mathrm{J}$ et al. Endotoxin exposure in cotton workers Am J Respir Crit Care Med (2005). 171 (2),Jan: 165-170.

11.Kazeer, Kh FY Lung Function Tests and Blood Gases in workers of Mishraq Sulphur Factory. Unpublished M.Sc. thesis, University of Mosul, College of Medicine.(1988).
12.Assoufi, B K Lung Function Tests in workers in some factories in Mosul area Unpublished M.Sc. thesis, University of Mosul, College of Medicine.(1979).

13. Oliver T. (1909).Quoted by Harris TR, JA, Killal, etal(1972).Byssinosis and respiratory diseases of cotton mill worker. Journal of occupational Medicine, 14;199.

14. Braunwald E, Fauci AS, Kasper DL, et al. Harrison's principles of internal medicine New York .McGrawHill.15 ${ }^{\text {th }}$ ed. (2001). pp:1528.

15.American Thoracic Society Questionnaire on respiratory Symptoms Am Rev Respir Dis (1978).118:1-120.

16.Mijnhardt Vicatest Dry Spirometer Manual foruse. GEBR.B.V Holland. (1984).

17. Harris M, Taylor G Medical statistics made easy isted. Martin Deutiz, USA, (2004).28-29.

18. Hankinson JL, Rosencrantz JR, Faden KB Spirometric reference values from a sample of general U.S. population Am J Respir Crit Care Med (1999).159: 179-187.

19. Hang $\mathrm{J}$ et al. Endotoxin exposure in cotton workers Am J Respir Crit Care Med 171 (2), Jan: (2005). $165-170$.

20.Bosse $r$, costa $\mathrm{m}$, podolsky s. Age, smoking inhalation, and pulmonary function. Arch Envirom Health; (1975). 35:247-252.

21.Jain SK, Gupta CK. Lung function in healthy men and women over forty. Ind .J.Med.Res. (1967)55;612.

22.Bande J, Van De Woes K.P. The influence of smoking habits And body weight on vital capacity andFEVI in male air force personnel: a longitudinal and cross-sectional analysis. Am Rev .Respir. Dis., (1980).122, 781-790.

23. Cotes JE (1975). Lung function in different stages in life. in: lung function, 3rd ed. Oxford Blackwell scientific publication .365-366.

24.Densen PM, Jones EW, and Bass A survey of respire Disease among New York City postal and transit workers. Env Respir (1989).2: 277.

25. Kondakis $X G$ and Pournares $N$ Byssinosis in cotton inneries in Greece. British $\mathrm{J}$ md Med (1985).22: 291.

26. William et al. Exposure to grain dust: Survey of the effects. Journal of Occupational Medicine. (1994). 6; 319. 
27. Cinkotai et al. Byssinotic symptoms among workers of 31 textile factory in Lancashire .Thorax (1990). 27: 82-90.

28.EL-Sadik YM, Moselhi M, El-Hinady AR, and Mostafa. Study of lung function changes among different grades of byssinosis. British $\mathrm{J}$ Ind Med (1982). 29:184.

29. Furness G,Mailand HB. Studies on cotton dust in relation on byssinossis part I bacteria and fungi in cotton dust bacteria and fungi in cotton dust.Brit J .Indust. Med, (1952). 2; 256.
30.Tuffnel P. experimental byssinosis. BritJ .Indust. Med, (1960). 18; 117.

31. Merchant et al. An industrial study of the biological 1effect of cotton dust and cigarette smoke exposure. Journal of Occupational Medicine (1972). 15: 212.

32.Ibrahim, M K. Effect of dusty atmosphere on the lung functions of workers of some factories in Mosul. Unpublished M.Sc. thesis, University of Mosul, Mosul College of Medicine Mosul.Iraq. (2006). 